\title{
Commentary \\ Insulin, intracerebral glucose and bedside biochemical monitoring utilizing microdialysis
}

\author{
Carl-Henrik Nordström
}

Department of Neurosurgery, Lund University Hospital, SE 22185 Lund, Sweden

Corresponding author: Carl-Henrik Nordström, carl-henrik.nordstrom@med.lu.se

Published: 31 March 2008

This article is online at http://ccforum.com/content/12/2/124

(c) 2008 BioMed Central Ltd

See related research by Schlenk et al., http://ccforum.com/content/12/1/R9
Critical Care 2008, 12:124 (doi:10.1186/cc6826)

\begin{abstract}
Following subarachnoid hemorrhage, hyperglycemia is strongly associated with complications and with impaired neurological recovery. Targeted insulin therapy for glycemic control might, on the contrary, have harmful effects by causing too low cerebral glucose levels. The study published by Schlenk and colleagues in the previous issue of Critical Care shows that insulin caused a significant decrease in the interstitial cerebral glucose concentration although the blood glucose level remained unaffected. Since several studies utilizing various analytical techniques have shown that cerebral blood flow and cerebral glucose uptake and metabolism are insulin-independent processes, the observation remains unexplained.
\end{abstract}

The study published by Schlenk and colleagues in the previous issue of Critical Care was initiated by clinical experience that, after subarachnoid hemorrhage, hyperglycemia is strongly associated with complications and impaired neurological recovery. Utilizing intracerebral microdialysis and bedside biochemical monitoring, Schlenk and colleagues made the unexpected observation that insulin caused a significant decrease in the interstitial cerebral glucose concentration although the blood glucose level remained unaffected [1].

The technique of microdialysis was introduced more than 30 years ago for monitoring the animal brain, and has become a standard technique in neuroscience with well over 11,000 publications [2,3]. Microdialysis was introduced as a routine technique within neurointensive care in 1995. The chemical variables generally analyzed and displayed at the bedside are those related to glycolysis (glucose, pyruvate, lactate) as well as those of glycerol and glutamate. A simplified diagram of intermediary metabolism is shown in Figure 1. The figure also shows data for these chemical variables in the normal human brain during wakefulness [4].
Since glucose is the main - or sole - substrate for cerebral energy metabolism under normal conditions, the possibility of measuring the glucose interstitial concentration is of obvious clinical interest. The calculated lactate/pyruvate ratio indicates the cytoplasmatic redox state, which reflects tissue oxygenation and the efficacy of oxidative metabolism. The ratio can be expressed in terms of the lactate dehydrogenase equilibrium: [NADH] $\left[\mathrm{H}^{+}\right] /\left[\mathrm{NAD}^{+}\right]=$[lactate] / [pyruvate] $\mathrm{x}$ $K_{\mathrm{LDH}}$.

As indicated in Figure 1, glycerol is related to intermediary energy metabolism. The glycerol level will accordingly vary with the cerebral metabolic rate [4]. The changes in the glycerol concentration caused by variations in the glycolytic rate are limited, however, and a marked increase in the cerebral glycerol level indicates degradation of the glycerophospholipids of the cell membranes [5]. The glutamate obtained by microdialysis of the cerebral interstitial space does not necessarily represent the excitatory transmitter. Since the reuptake of extracellular glutamate - into astrocytes as well as into neurons - is energy dependent, an increase in the interstitial glutamate concentration appears a sensitive indicator of cerebral energy deficiency [6].

The intracerebral glucose concentration obtained from microdialysis reflects the balance between transport of the substrate into the tissue and its intracellular consumption. The decrease in the interstitial glucose level described by Schlenk and colleagues might tentatively be explained by a change in delivery (decreased blood flow, reduced transport across the blood-brain barrier) and/or in consumption (increased intracellular uptake) [1].

The effect of insulin on regional cerebral blood flow was evaluated in 10 diabetic men utilizing quantitative dynamic positron emission tomography scanning of labeled water 


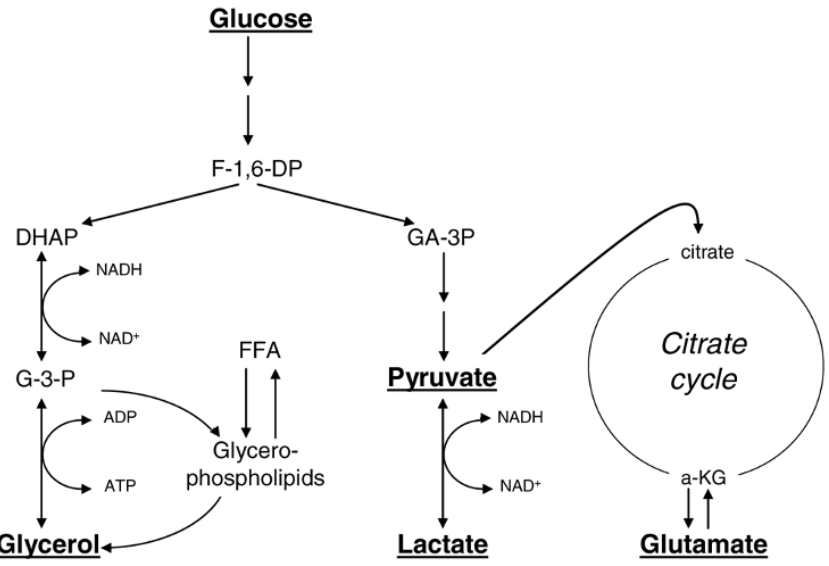

$\begin{array}{ccccccc}\text { Normal } & \text { Glucose } & \text { Lactate } & \text { Pyruvate } & \text { La/py ratio } & \text { Glutamate } & \text { Glycerol } \\ \text { human brain } & 1.7 \pm 0.9 & 2.9 \pm 0.9 & 166 \pm 47 & 23 \pm 4 & 16 \pm 16 & 80 \pm 40 \\ \text { (perfusion rate } & \mathrm{mmol} / \mathrm{L} & \mathrm{mmol} / \mathrm{L} & \mu \mathrm{mol} / \mathrm{l} & & \mu \mathrm{mol} / \mathrm{l} & \mu \mathrm{mol} / \mathrm{l} \\ 0.3 \mu \mathrm{l} / \mathrm{min} \text { ) } & & & & & & \end{array}$

Glycolytic chain intermediary metabolism, glycerol and glycerophospholipid formation and the citric acid cycle. Simplified diagram of the intermediary metabolism of the glycolytic chain and its relation to the formation of glycerol and glycerophospholipids and to the citric acid cycle. Underlined metabolites are measured at the bedside with enzymatic techniques. Reference levels for normal human brain (during wakefulness) are presented [4]. F-1,6-DP, fructose-1,6-diposphate; DHAP, dihydroxyacetone-phosphate; GA-3P, glyceraldehyde-3-phosphate; G-3-P, glycerol-3phosphate; FFA, free fatty acids; La/py, lactate/pyruvate; a-KG, $\alpha$-ketoglutarate.

$\left(\mathrm{H}_{2}{ }^{15} \mathrm{O}\right)$ [7]. The investigation showed that insulin did not affect the cerebral blood flow. In the present study a significant decrease in cerebral blood flow might have been caused by other factors. The presented biochemical data, however, do not support this hypothesis. During a gradual decrease in cerebral blood flow, the oxygen supply to the brain will be insufficient - reflected in an increased lactate/ pyruvate ratio - before the supply of substrate is seriously jeopardized. In the present study, intracerebral glucose decreased but the lactate/pyruvate ratio remained constant.

The central nervous system has conventionally been considered an insulin-insensitive tissue. As early as 1978, however, it had already been reported that insulin receptors were widely distributed within the brain [8]. The functions of insulin receptors and their expression in the developing and adult brain have become the focus of recent research [9]. The intracerebral insulin receptors appear to have a different role from those in the periphery. Insulin enters the central nervous system through the blood-brain barrier by a receptor-mediated saturable transport system $[10,11]$, and little or no insulin is produced within the brain. Quantitative dynamic positron emission tomography scanning of ${ }^{18} \mathrm{~F}-$ labeled deoxyglucose in diabetic man has shown that the brain glucose metabolism is not sensitive to the insulin concentration within the physiologic range [7]. By utilizing magnetic resonance techniques $\left({ }^{1} \mathrm{H}\right.$ magnetic resonance spectroscopy), the majority of cerebral glucose uptake/ metabolism has been documented as an insulin-independent process in healthy subjects [12].

Experimental studies have indicated that insulin and insulin receptor signal transduction have several other important physiological functions in the brain. These functions include food intake, inhibition of hepatic gluconeogenesis, counterregulation to hypoglycemia, reproduction, modulation of tau phosphorylation, metabolism of amyloid precursor protein and $\beta$-amyloid clearance, neuronal survival, and memory [9].

Since the observation by Schlenk and colleagues is not explained by a decrease in cerebral blood flow or by the direct effect of insulin on cerebral glucose uptake and metabolism, we may finally ask whether the interstitial glucose concentration (evaluated by microdialysis) might be different from the glucose intracellular concentration [1]. This is probably not the case. The extracellular glucose concentration in the mammalian brain measured with glucose-specific microelectrodes [13] showed levels very similar to those for the whole brain measured by magnetic resonance [14]. These results are in accordance with ${ }^{1} \mathrm{H}$ magnetic resonance studies of the human brain during euglycemia and hyperglycemia showing that glucose is distributed throughout the entire cerebral aqueous phase [15]. Accordingly, we have no data supporting the hypothesis that insulin would affect the cerebral extracellular/intracellular glucose ratio. 
The observation that insulin decreases the cerebral extracellular glucose concentration even when the blood glucose level remains unaffected is difficult to explain and would need further confirmation before it is generally accepted. The study by Schlenk and colleagues, however, is an important indication that microdialysis may be used at the bedside to adjust and optimize intensive care therapy.

\section{Competing interests}

The author declares that they have no competing interests.

\section{References}

1. Schlenk F, Graetz D, Nagel A, Schmidt M, Sarrafzadeh AS: Insulin-related decrease in cerebral glucose despite normoglycemia in aneurysmal subarachnoid hemorrhage. Crit Care 2008, 12:R9.

2. Ungerstedt $\mathrm{U}$, Pycock $\mathrm{CH}$ : Functional correlates of dopamine neurotransmission. Bull Schweiz Akad Med Wiss 1974, 1278: 1-5.

3. Ungerstedt U: Microdialysis - principles and application for studies in animal and man. J Intern Med 1991, 230:365-373.

4. Reinstrup P, Ståhl N, Hallström A, Mellergård P, Uski T, Ungerstedt $\mathrm{U}$, Nordström $\mathrm{CH}$ : Intracerebral microdialysis in clinical practice. Normal values and variations during anaesthesia and neurosurgical operations. Neurosurgery 2000, 47:701-710.

5. Hillered L, Valtysson J, Enblad P, Persson L: Interstitial glycerol as a marker for membrane phospholipid degradation in the acutely injured human brain. I Neurol Neurosurg Psychiatry 1998, 64:486-491.

6. Samulessson C, Hillered L, Zetterling M, Enblad P, Hesselager G, Ryttlefors M, Kumlien E, Lewén A, Marklund N, Nilsson P, Salci K, Ronne-Engström E: Cerebral glutamine and glutamate levels in relation to compromised energy metabolism: a microdialysis study in subarachnoid hemorrhage patients. J Cereb Blood Flow Metab 2007, 27:1309-1317.

7. Cranston I, Marsden P, Matyka K, Evans M, Lomas J, Sonksen P, Maisey M, Amiel SA: Regional differences in cerebral blood flow and glucose utilization in diabetic man: the effect of insulin. J Cereb Blood Flow Metab 1998, 18:130-140.

8. Havrankova J, Roth J, Brownstein M: Insulin receptors are widely distributed in the central nervous system of the rat. Nature 1978, 272:827-829.

9. Plum L, Schubert M, Brüning JC: The role of insulin receptor signaling in the brain. Trends Endocrinol Metab 2005, 16:5965.

10. Margolis RU, Altszuler $\mathrm{N}$ : Insulin in the cerebrospinal fluid. Nature 1967, 215:1375-1376.

11. Woods SC Porte D: Relationship between plasma and cerebrospinal fluid levels in dogs. Am J Physiol 1977, 233:E331E334.

12. Seaquist ER, Damberg GS, Tkac I, Grutter R: The effect of insulin on in vivo cerebral glucose concentrations and rates of glucose transport/metabolism in humans. Diabetes 2001, 50: 2203-2209.

13. Silver IA, Erecinska M: Extracellular glucose concentration in mammalian brain: continuous monitoring of changes during increased neuronal activity and upon limitation in oxygen supply in normo-, hypo-, and hyperglycaemic animals. $J \mathrm{Neu}^{-}$ rosci 1994, 14:5068-5076.

14. Mason GF, Behar KL, Rothman DL, Shulman RG: NMR determination of intracerebral glucose concentration and transport kinetics in rat brain. J Cereb Blood Flow Metab 1992, 12:448455.

15. Gruetter R, Novotny EJ, Boulware SD, Rothman DL, Shulman RG: ${ }^{1} \mathrm{H}$ NMR studies of glucose transport in the human brain. J Cereb Blood Flow Metab 1996, 16:427-438. 